\title{
A New Concept and a New Model for the Education of Translation Competence in Chinese Mainland Setting
}

\author{
Weimin Yuan \\ Assumption University \\ Bangkok, Thailand \\ Foreign Trade and Business College \\ Chongqing Normal University \\ Chongqing, China
}

\begin{abstract}
This article subverts traditional way to explore the definition of translation competence and its development. Based on dialectical thinking and system theory, division and integration are combined to develop translation competence. Elements at different levels are integrated into another system at higher level as one of elements waiting for another integration at another higher level. At each stage, corresponding competence is required and corresponding courses are used to integrate sparse knowledges and skills to meet corresponding competence requirements. A new concept and a new model are presented only with an aim to shed light on exploration of translation competence and its development in educational setting in Chinese mainland.
\end{abstract}

Keyword-division; integration; combination; translation competence; Chinese mainland

\section{INTRODUCTION}

Translation competence is not a new topic academia. Since it came into scholars' vision. It has been heatedly discussed for long. Scholars often attach great importance to the constitution of translation competence, building a lot of instructive and functional models. Furthermore, long-time persistence in this topic makes great contribution to the development of translation studies, especially to great extent, speeding up the shifting from academic research to applied research. It draws more and more attention to the field of translation practice. However, while achievements are reviewed, theoretical contribution is not easy to be found. Since at the very beginning, the division of translation competence becomes the central job for academia. The very key point lies in the fact that the division of translation competence cannot present operative model for education or teaching. All models seem to be a bit abstract. Typical cases often refer to the models of EMT (2006) and PACTE (2003). To some extent, they only show the core constituents of translation competence. How the constituents develop into competence, even professional competence still a puzzlement in academia. In another words, except the division of translation competence, there is no further realization of the nature of translation competence. There is no real further contribution to theoretical development in this respect for translation studies. In order to enrich translation theory and find real effective remedy for the problems in Chinese mainland education of translation, in this paper, one concept and one model will be presented to get response from academia for real constructive methods for education setting. Before the further discussion, related introduction to translation education and teaching in China need to be presented as a scope or setting for the topic of this paper.

\section{A. Brief Introduction to Translation Education in Chinese Mainland}

1) History: Translation education has a long history in China. In the climax of the spread of Buddhism in Tang Dynasty in 645 translation workshop was opened up by Xuan Zang. It is the earliest record of translation education in China. In next Dynasty of Song, special translation academy is set up for translating scriptures. Then in Yuan Dynasty, a special school for translation is built as education institution to educate translation talents. In Ming Dynasty, larger special translation school, $\mathrm{Si} \mathrm{Yi}$ Academy, is established to meet with the needs of diplomatic communication for translators and interpreters. In Qing Dynasty, there are serval translation schools including $\mathrm{Si}$ Yi in Ming Dynasty. Among them the most famous one is Tung Wen School. From 1862 to 1902 it produced many students often as foreign language teachers and translation talents. Until 1902, it integrated itself into Capital University, the predecessor of Beijing University. This is the formal starting point of translation education in higher education. (Bing Xie, 2005) During anti-Japanese war, in 1944, for the purpose of military and diplomacy, a foreign language school set up in Yan'an came into existence for training translation talents needed. It offered translation and interpreting courses, starting the official education of translation talents in mainland China. It exerts great influences over the following development of translation teaching. After the founding of People's Republic of China, languages schools mushrooms. Because of historic and 
political reasons, Russian language gains its popularity. At that time, translation teaching is only as one excise to improve the level of foreign language (Lei Mu, 1999). Until 1978, when China comes into a new era, translation teaching appears in the different types of colleges and universities. Real and official translation teaching has developed rapidly in terms of both quantity and quality in mainland China (Ibid). On April 12, 1979, translation teaching as a compulsory course gains its official status coming into the list of a new syllabus of compulsory courses for English teaching. In 2004, Shanghai International Studies University was approved as the first university to start doctoral degree of translation studies. In 2006, three universities are allowed to grant a BA degree in translation. In 2007, MTI (Master of Translation and Interpreting) is approved to be set up in 15 universities. Since then, translation education in China has established a complete three-tier system from BA through MA to $\mathrm{PhD}$, gaining its independent status away from foreign language teaching.

2) Development of Translation Education: Up to now, the development of Chinese Translation has experienced three crucial points: in 20o4, $\mathrm{PhD}$ of Translation Studies; in 2006, BA degree in translation; in 2007, Master degree of Translation and Interpreting (Chao Wei Zhu, 2014). It is officially accepted as one member on the list of majors in colleges and universities, pushing its development to a new level (Hong Ping, 2014). From the starting of BA degree of translation in mainland China, the number of universities or colleges with BA degree of translation jumps from 3 to 230(Ping Hong,2016). In 2014, the number of students majoring in translation rises up to 14693 (Yi Shi, 2015). The progress of development of translation education will be further pushed by "One Belt and One Road" policy initiated by China. In 2017, many minority foreign languages are accepted as new majors to meet the needs for translation talents under the environment of grand foreign policy of "One Belt and One Road".

\section{3) Present Problems:}

a) The Problem in Reality: The fast development of translation education has to face the more and more difficult issue of students' employment. According to the news from the Ministry of Education of the People's Republic of China, in this year (2017) the number of graduates amounts to 7.95 million, near to the half of the total capacity of new increase employment, but employment positions available are far from the needs of the pool of labor force because of the downturn of economy in the world. But for translation major, the tough issue of employment lies in two aspects: on the one hand, the rocket-like rise of translation majors in recent years causes quality problem of education (Hong Ping, 2013). In early 2009, this issue was raised by Hualing Pan and Bingfei Liu. It means talents only with language knowledges and single translation skills cannot meet with the present social needs. Each year only a small number of students majoring in Translation get a job in the field of translation related. It is a very ironical reality that on the one hand, translation market needs qualified translation talents; on the other hand students cannot find corresponding jobs because of their incompetence to meet with its needs. Obviously how to educate students' translation competence naturally comes into spotlight in the Translation education. In fact, for long quality of higher education in China has been questioned by the republic, it is also a touchy issue for scholars and related education institutions. Thus, in 2011, the Coordinating Team of Teaching of Translation of Ministry of Education of People's Republic of China issues "The Guideline for Teaching of BA Degree of Translation Major in Universities and Colleges" as a means to make quality assured. In 2013, the team started "National Standard of Teaching of BA Degree of Translation Major", and in 2017 the standard will be issued officially. It is a blessing for Translation Education in China (Weihe Zhong, Junfeng Zhao, 2015). In the interpretation of "The Guideline for Teaching of BA Degree of Translation Major in Universities and Colleges". Ping Hong obviously explained translation competence as comprehensive professional translation competence, though at the level of lower intermediate or intermediate level (2014), which is to the point of translation teaching in China. His further discussion is found in his interpretation of "National Standard of Teaching of BA Degree of Translation Major" (2015). From his analysis, lacking of professional translation competence is the core problem of translation teaching. Similar idea is voiced by Chaowei Zhu (2014). He showed readers a fact that deviation or vague education objectives of colleges and universities with BA degree of translation major, often blur the difference between professional translation talents and foreign language talents. As PACTE (2000) has pointed out, quite rightly, the development of translation competence in student translators today not only means the training of their linguistic-cultural skills, but also other related aspects such as IT skills, marketing and other related problem-solving abilities as well (Mackenzie 2004: 32-33; Kiraly 1995, 2000)(Zaixi Tan,2008). Undoubtedly, the education of professional translation competence is the starting point but how to educate students' professional translation competence is natural question as followed.

b) Problems in Research: As for problem above mentioned, the only way to develop students' competence, especially their professional translation competence, that is, work ready competence, not the competence staying at the level of knowledges and skills. How to develop students' professional competence arouses many scholars desire for study. They have made great efforts to it and achieve great success in some aspects. Until 2014, papers about this aspect, has reached to 1000 pieces (jingmin $\mathrm{Fu}, 2015$ ). However, only serval scholars involve the problem of the development at each stage in the whole process (Zaixi Tan, 2008; Heping Liu, 2011; Shuhuai Wang, 2012). They lineate different stages of translation competence, even details the content at each stage and the relation between constituents. However at each stage, how all constituents are integrated and even developed into one type competence as 
foundation for next stage is not clear. It is worthy to be discussed further. In the next section, a new concept and a new model are raised to explore the further discussion about how to develop students' professional competence.

\section{COMBINATION OF DIVISION AND INTEGRATION AS A CONCEPT FOR A NEW MODEL FOR DEVELOPING PROFESSIONAL TRANSLATION COMPETENCE}

\section{A. Rationale}

Translation competence came into vision of scholars 1970 's. Since the very beginning of its appearance in the academia, it is has long been the focus of academia. Too many scholars care about how it constitutes itself. How to educate translation competence naturally revolves the division of translation competence or constituents of it. Up to now, the black box still remains unsolved. Why academia is crazy about what consists of translation competence comes from human being's nature and curiosity. Another pragmatic reason lies in educating translation competence. Indeed, long-time persistence in doing this is very fruitful for academic research and translation education. However, from the perspective of dialectics, scholars only do the things of one side. They try their best to divided translation competence into serval sub-competencies and based on this seek the way to develop it. In fact, the other side is overlooked by them because they are so crazy about what they on earth are in the black box of translation competence. It is very just like a coin with two sides. The other side is the opposite of the today's division. It is integration. This can be detected from the definition of translation competence by PACTE. The translation competence is defined in following paragraph:

Translation competence is the underlying system of knowledge needed to translate. It includes declarative and procedural knowledge, but the procedural knowledge is predominant. It consists of the ability to carry out the transfer process from the comprehension of the source text to the reexpression of the target text, taking into account the purpose of the translation and the characteristics of the target text readers. It is made up of five sub-competencies (bilingual, extra-linguistic, knowledge about translation, instrumental and strategic) and it activates a series of psychophysiological mechanisms (PACTE, 2003).

If from the angle of text analysis of this paragraph, serval synonymous mini-structures can be found such as "underlying", "include", "consist of", and "is made up of". These mini-structures may mislead readers to the very focus of division, or to some extent, stimulate readers' inner desire for exploring the constitution of translation competence. Possibly PACTE also overlook the fact that the way of introducing or defining translation competence may simplify the study of translation competence. Though the model built by PACTE is the most pragmatic one in education setting, it may guide scholars in a wrong way. Furth reading this paragraph above word by word can show the very part under the iceberg. The very core word is "system". To be frank, the definition at the beginning of the paragraph cited above is so simple but meaningful once tasted again and again. But the focus our attention of PACTE at that time is division rather than "system". In the later research of PACTE, no further details about "system" is found. It seems a miss or a gap now but from the very expression of "underlying system" suggests that translation competence is a system which consists of sub-competencies. In term of system theory, system consists of elements in a logic and organic way. Elements in a system are not added simply together. They are systemized by the special law of system. Once elements come into a system, on the one hand, elements have their own nature different from others in the system, on the other hand, they own special nature bestowed by the system. Once system broken, elements are sands like in the beach without the function or nature of system on the whole. Thus from the definition of translation competence by PACTE, it is a systematic competence. Mechanic division only serves for some special purpose such as identifying core subcompetencies so as to educate them step by step. In this way professional translation competence is often divided into several sub-competencies, of which is made up of several types of knowledges and skills, then design corresponding courses to match with them, and teaching is used to make professional translation competence achieved gradually. Such a route or idea of how to educate students' professional translation competence is clearly expressed by Liu Heping (2011). The detailed exploration of training in different phases of interpreting comes from her longtime teaching experience and persistent research on interpreting teaching. However, each phase only comes from mechanic division not from natural evolution or movement. It means knowledges and skills in each phase cannot automatically transform into competence. Without transformation in nature, knowledges and skills still remain unchanged as they are. Though her following recommended teaching methods are instructive, understanding only at this level leaves this matter unsolved. All knowledges and skills have to be boiled up into a comprehensive competence just like a stove of soup of different vegetables and meat, as is show in the following "Fig. 1".

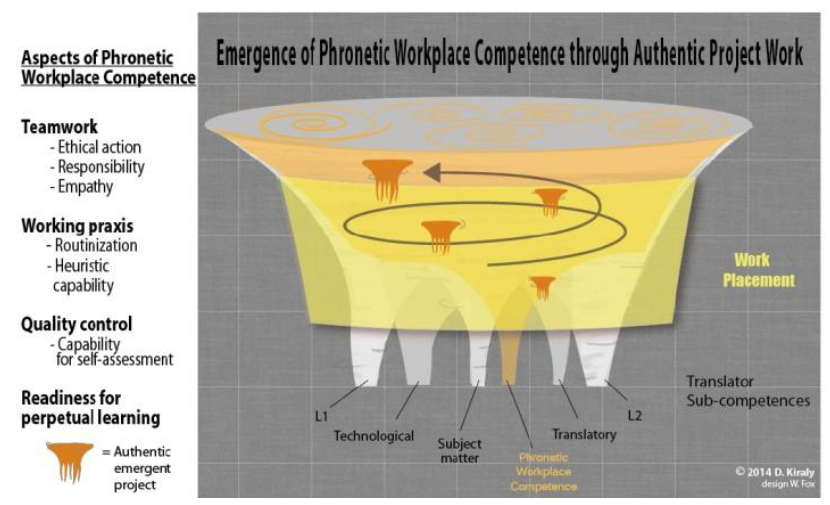

Fig. 1. Kiraly, 2014.

In this stove, all knowledges and skills are melted, and deposed, and mix with others, and achieve their transformation. In Liu Heping's idea about how to educate students' professional translation competence at each phase, it is obvious that integration of all knowledges and skills at each phase is absent. This type of lacking of integration 
makes next phase lack essential foundation with the form of competence, keeping this way to end. Thus once professional translation competence serves as the orientation of translation education or teaching, all knowledges and skills have to be integrated and transformed.

From the construction of translation major, there also exist two issues to be dealt with.

First, how translation major makes itself as it is?

In fact, it is still an obvious question needed to be answered by academia though translation major has been set up in Chinese mainland for 11 years. If all schemes of translation education of translation majors and those of foreign language majors in China are gather together, the very impression is that they all come from the same manufacturer. The situation is worse in some average colleges or universities. What happened to this? It comes from colleges or universities themselves. It seems to be partially right. Another reason is the problem of system. Under present established system, students of translation major still have their own tests. They attend their tests as foreign language students do. For example, translation students with English-Chinese language pair have to attend Test 4 and Test 8 for English Major. Even for English major, students have only Test 4 and Test 8 . Test 8 is not essential element for graduation. So in many colleges and universities, foreign language students and translation students have only one Test 4 . Here one point is aimed to made that from first year to four year students majoring in translation is educated at random only under the control of some separate curricula at each stage. Furthermore, these curricula are similar to each other without obvious difference between what belongs to translation major and what belongs to foreign language major. This is worse in last two years. A number of students are reduced to mediocrity only waiting for graduation without any competence for future life. Through the whole education system, there is no way to stimulate students at corresponding stage. Translation is a profession in nature (Jean. Delisle, 1998). This very simple sentence tells the basic difference between translation major and foreign language major. This means all curricula that appear in translation major must be different from those appearing in translation major, even if they share same course names. The nature of translation decides its transcendence from level of languages and knowledges or skills. In this sense, integration is also needed to get sparse knowledges and skills into a certain level of competence. Thus, it is high time that different thinking is used, not division but the combination of division and integration makes translation competence formed as a working system.

\section{B. The Combination of Division and Integration}

1) Theoretical Framework: Division and integration are based on dialectic thinking and system theory. The two ways with different directions are used to guide the research and teaching of translation competence. Division serves as a means to learn the composition of translation competence. Its aim is to find concrete way to develop translation competence. Meanwhile, based on the division all elements are integrated in a system. The system continues to serve as an element into another higher system, and on and on. The process can be described as following formulas.

a) The Division Process:

\section{First Division \\ Translation Competence $=\mathrm{A}+\mathrm{B}+\mathrm{C}+\ldots+\mathrm{N}$}

Second Division

$\mathrm{A}=\mathrm{A} 1+\mathrm{A} 2+\mathrm{A} 3+\ldots+\mathrm{An}$

$\mathrm{B}=\mathrm{B} 1+\mathrm{B} 2+\mathrm{B} 3+\ldots+\mathrm{Bn}$

$\mathrm{C}=\mathrm{C} 1+\mathrm{C} 2+\mathrm{C} 3+\ldots+\mathrm{Cn}$

…

$\mathrm{N}=\mathrm{N} 1+\mathrm{N} 2+\mathrm{N} 3+\ldots \mathrm{Nn}$

Third Division

$$
\begin{aligned}
& \mathrm{A} 1=\mathrm{A} 11+\mathrm{A} 12+\mathrm{A} 13+\ldots+\mathrm{A} 1 \mathrm{n} \\
& \mathrm{B} 1=\mathrm{B} 11+\mathrm{B} 12+\mathrm{B} 13+\ldots+\mathrm{B} 1 \mathrm{n} \\
& \mathrm{C} 3=\mathrm{C} 11+\mathrm{C} 12+\mathrm{C} 13+\ldots+\mathrm{C} 1 \mathrm{n} \\
& \ldots \\
& \mathrm{Nn}=\mathrm{N} 11+\mathrm{N} 12+\mathrm{N} 13+\ldots \mathrm{N} 1 n
\end{aligned}
$$

b) The Integration Process:

First Integration

$\mathrm{A}+\mathrm{B}+\mathrm{C}+\ldots+\mathrm{N}=$ Translation Competence

Second Integration

$$
\begin{aligned}
& \mathrm{A} 1+\mathrm{A} 2+\mathrm{A} 3+\ldots+\mathrm{An}=\mathrm{A} \\
& \mathrm{B} 1+\mathrm{B} 2+\mathrm{B} 3+\ldots+\mathrm{Bn}=\mathrm{B} \\
& \mathrm{C} 1+\mathrm{C} 2+\mathrm{C} 3+\ldots+\mathrm{Cn}=\mathrm{C} \\
& \ldots . \\
& \mathrm{N} 1+\mathrm{N} 2+\mathrm{N} 3+\ldots \mathrm{Nn}=\mathrm{N}
\end{aligned}
$$

Third Integration

$$
\begin{aligned}
& \mathrm{A} 11+\mathrm{A} 12+\mathrm{A} 13+\ldots+\mathrm{A} 1 \mathrm{n}=\mathrm{A} 1 \\
& \mathrm{~B} 11+\mathrm{B} 12+\mathrm{B} 13+\ldots+\mathrm{B} 1 \mathrm{n}=\mathrm{A} 2 \\
& \mathrm{C} 11+\mathrm{C} 12+\mathrm{C} 13+\ldots+\mathrm{C} 1 \mathrm{n}=\mathrm{C} 3 \\
& \ldots \\
& \mathrm{N} 11+\mathrm{N} 12+\mathrm{N} 13+\ldots \mathrm{N} 1 \mathrm{n}=\mathrm{Nn}
\end{aligned}
$$

\section{$\mathrm{N} 11+\mathrm{N} 12+\mathrm{N} 13+\ldots \mathrm{N} 1 n=\mathrm{Nn}$}

$\mathrm{N} 1 \mathrm{n}$ is a small element or system. $\mathrm{Nn}$ is a bigger system than N1n. But $\mathrm{N}$ is still an element in another bigger system. $\mathrm{Nn}$ can be further divided. Owing to limited space, the formula only is a simple description of the movement of integration or division of the development of translation competence.

This is different from present single-sided division of translation competence. The two ways are essential for understanding translation competence. The division aims to learn the nature of translation competence; the integration is 
to learn how translation competence is gained from the hierarchy development, which often involves education of translation competence. Only with the two directions combined, translation competence can be achieved in educational setting.

1) Competence Frameworks at Each Stage: the development of translation competence is a process. It needs covers a series of stages. Each stage competence has its corresponding features from other stages. In educational setting, in order to educate students' translation competence, the development of translation competence is based on four stages of four years. The process of development of translation competence can be shown as following "Fig. 2".

$$
\begin{array}{l|l|l|l} 
& & \text { Fourth } \\
\text { stage }
\end{array}
$$

Fig. 2. The process of development of translation competence.

The first stage is the first year, it features with linguistic knowledges and other related knowledges. In this stage, linguistic knowledge is core element. Some people many think it is far away from translation competence. It is a misunderstanding. Translation major is radically different from foreign language major not in the final realization of translation competence but in the practical consideration, even professional consideration at the very beginning of learning and teaching. It means in this stage different types of knowledges have to be integrated, especially linguistic knowledges and instrumental knowledges have to be integrated into a special competence. Only with such an integration, the practicality of translation can be represented, which is required by the nature of translation. In another words, in this stage, linguistic knowledge has to be linked with translation competence; instrumental knowledges and other related knowledges all have to be digested as a foundation for the development of translation competence. The integration plays the role as the small triangle in the figure above. In this way, the burden in next stage can be lessened. The very focus or attention is placed on what should be developed at that stage. Along this line, translation competence is gained gradually.

The second stage is the second year. In this stage, in nature, it still belongs to linguistic stage. But it is basic different from the first stage in two aspects. First, besides the language level required by foreign language major, the linguistic level has to be raised to translation and interpreting. This means in the end of second year, students can do basic translation and interpreting. Second, instrument competence has to be realized in this stage, even including enough contact with computer-aided translation means or software.

The third stage is the third year. Third year is the key stage with all knowledges and skills melted here. In this stage, no attention are paid to single aspect. Different types of competencies have to appear, even beginning to form comprehensive competence. The very core of this stage is to facilitate the formation of transfer competence. Instrumental competence is real facilitator of the development of transfer competence. This combination of this two types of competence is required in next stage.

The fourth stage is the fourth year. It is the very stage that professional translation competence can be gained. In this stage, training or exercise has to be replaced by work, though in classroom. It means simulating is the main form to make students work as professionals do. It is a stage to be familiar with professional ethics and procedures, transforming students from novice to professional with their self-awareness and self-confidence just like a real translator. In this stage, professional translation competence can be achieved, at least partially achieved; on other hand, it is a stage for students to work as professionals do, preparing themselves for internship in forthcoming year.

2) Curriculum Framework: In order to achieve the competence index mentioned above, each stage has to design some comprehensive courses to speed up the integration of all knowledges and skills, especially some key knowledges and skills from the angle of professional translation competence.

In fist stage, linguistic courses have to be designed from translation major not from foreign language major. Listening and speaking, even writing and reading can be integrated as a comprehensive course with great challenge in these aspects. These courses can be recommended as followings: Speech Contest, Dubbing Contest, Dictation Contest, Reading and Writing Contest, learning portfolio presentation or contest, especially the combination of these forms with two or more aspects. Attention is paid to get all students involved in different courses or activities. This aims to develop student's comprehensive competence required for translation and interpreting. Instrumental knowledges should be integrated into these courses.

In second stage, listening, speaking, writing, and reading finally integrate each other, forming basic translation and interpreting ability based on instrumental competence. Some comprehensive course are needed to speed up the integration. This type of courses centers on translation and interpreting. Instrumental knowledges have to develop into instrumental competence. This is often overestimated by academia. Some courses often appear in the third year or third stage. It is a bit late. Instrumental competence needs a long time to form, especially only formed in the use. This means earlier use in translation training does more benefit to the development of translation competence. The extent of combination of instrument and translation is the representation of professionalism. In this stage in order to represent the professional nature of translation, integration courses can be designed for preparing students for the Test of Preliminary Certificate for Translator and Interpreter. Meanwhile, simple and basic simulation of professional interpreting and translation can be used here. The very focus is on the integration of linguistic knowledges and instrumental competence but the professional procedure and the nature of profession man stimulate student's greatest curiosity and interest in future career. This is often underestimated by 
academia. At each stage some incentives have to be found so that students can be pushed stage by stage.

In the third stage, transfer competence is the very focus. It needs comprehensive courses to facilitate the process of integration. In translation, texts need to be a bit longer and tend to applied texts, especially within time constraints and quality requirement. Interpreting needs combination of listening, speaking, and writing with time pressure and quality required. The very key point lies in the completion with confidence. Translation instruments have to be integrated into these comprehensive courses as one facilitator and one sub-competency of translation competence. In fact, from the first stage to the fourth stage, translation instruments have to be paid more attention to, even in real professional career, instrument competence is still key aspect for a professional to improve continually. Meanwhile, preparation for Test for Intermediate Certificate of Translator and Interpreter must be added into comprehensive courses. Besides great contribution to the development of translation competence, it is a way to direct students towards professional career. This stage still needs simulating courses in translation and interpreting, especially focusing the attention on students' inclination of direction, such as interpreting or translation. The difference of simulation here is from that at last stage in the emphasis on professionalism, preparing for next year's internship.

In the fourth stage, courses almost comprehensive practice course. It means use authentic material and working procedure to do translation or interpreting as in real working condition. The teaching material, teaching procedure, and assessment of translation and interpreting are decided by professional standard. These courses often appear as project or workshop, even students' translation company with all the aspects needed integrated within these courses. The realization of profession, profession ethics, and professional strategy are essential elements in these courses. The comprehensive courses can be divided by direction, with one semester for one direction and the other semester for the other one. Translation and interpreting can be designed respectively. Comprehension, authenticity, and procedure are the features of courses in this stage. But, internship has to take up some time of this stage, even the majority of this stage, each college or university has different situations. It can be flexible, even with the combination of the third stage and the fourth stage. In this way, authentic stimulating courses are possibly placed in the second semester of third year and the first semester of the fourth year.

\section{CONCLUSION}

From the discussion above, the paper aims to reveal the two-side nature of exploring translation competence. Scholars often divides translation competence into subcompetencies with functional aim, partly because of the first deductive thinking. Based on system theory, the papers uses inductive thinking to establish a ladder from knowledges and skills to competence, even competence to competence, the gradual rising order from bottom to top. In fact, there is nothing wrong in two thinking ways. Division lies in details or elements; integrating in system or unity. Based on division of translation competence, integration can form comprehensive knowledges and skills, further to competence not only separate or pieces of knowledges and skills. This highlights what should be achieved at corresponding stage through corresponding courses. Further this not only cares about specific competence but also uses comprehensive courses to make it come true. The emphasis is greatly placed on the development of instrumental competence is that it is the typical sign of professional translation competence in an era of information age. This means from the first stage professionalism is the very nature representing translation major rather than foreign language major.

\section{REFERENCES}

[1] EMT expert group (2009a). Competences for professional translators, experts in multilingual and multimedia communication. http://ec.europa.eu/dgs/translation/programmes/emt/key_documents/e mt_competences_translators_en.pdf (consulted 10.07.2011)

[2] PACTE, "Building a translation competence model," Fabio Alves (Ed) Triangulating translation: perspectives in process oriented research. Amsterdam: John Benjamins, 2003, 43-66.

[3] Bing Xie, "The Influence of Chinese Ancient Translation Workshop over the Later Translating Activities," Journal of Huainan Teachers College, 2005.

[4] Lei, Mu. "Translation Teaching in China," Meta 441 (1999): 198-208. Ibid.

[5] ChaoWei Zhu, "Development of Translation Education in Chongqing: Status Quo, Problems and Solutions," Foreign Language and Literature, 2014, pp106-111.

[6] Yi Shi, "The Education of Translation Talents and the Reform of Translation Teaching under the Environment of the Grand Diplomacy," The Joint Conference of English Teachers in Beijing Region, 2015.

[7] Hong Ping, "The Education of Professional Translation and the Training of Professional Proficiency," China International Language Service Conference, 2013.

[8] Hualing Pan, Bingfei Liu, "Training of Translation Talents in Local Institutions: Problems and Solutions," Jounal of Yichun College, 2009.

[9] Weihe Zhong, Junfeng Zhao, "The Interpretation of National Quality Standard of BA Degree of Translation Major,” 2015, p289-296.

[10] ChaoWei Zhu, "Development of Translation Education in Chongqing: Status Quo, Problems and Solutions," Foreign Language and Literature, 2014, pp106-111.

[11] Zaixi Tan, "Towards a Whole-Person Translator Education Approach in Translation Teaching on University Degree Programmes," Meta: journal des traducteurs / Meta: Translators' Journal, vol. 53(3), 2008, p. 589-608.

[12] Jingmin $\mathrm{Hu}$, "Translational Competence: Retrospect and Outlook," Foreign Language Learning Theory and Practice, 2015, p80-86.

[13] Zaixi Tan, "Towards a Whole-Person Translator Education Approach in Translation Teaching on University Degree Programmes," Meta: journal des traducteurs / Meta: Translators' Journal, vol. 53(3), 2008, p. $589-608$

[14] Heping Liu, "The Periodicity of Translation Competence," Chinese Translator Journal, 2011, p37-45.

[15] ShuHuai Wang, "On Translation Teaching," Shanghai Foreign Language Education Press, 2013.

[16] PACTE, "Building a translation competence model," Fabio Alves (Ed) Triangulating translation: perspectives in process oriented research. Amsterdam: John Benjamins, 2003, 43-66.

[17] Heping Liu, "The Periodicity of Translation Competence," Chinese Translator Journal, 2011, p37-45. 
[18] Kiraly, "Towards an Emergent Curriculum Development Model for the European Graduate Placement Scheme," International Conference The Future of Education, 4th Edition, 2014.

[19] Delisle, Jeanet Hannelore Lee-Jahnke (dir.) (1998), Enseignementde la traduction et traduction dans l'enseignement, selection of text spresented at the Colloquede Créteil (France) in April 1997, Ottawa: University of Ottawa Press. 